\title{
Design and Performance of a Bidirectional Isolated Dc-Dc Converter for Renewable Power System
}

\author{
Dr.K.Ravichandrudu ${ }^{1}$, Sk.Fathima ${ }^{2}$, Mr.P.Yohan Babu' ${ }^{3}$ Mr.G.V.P.Anjaneyulu ${ }^{4}$ \\ ${ }^{1,2,3}$ Krishnaveni Engineering College for Women,Narasaraopet, Guntur,AP,India. \\ ${ }^{4}$ Reaserch scholar SVU College of engineering,S.V.U.,Tirupathi.
}

\begin{abstract}
This paper contributes to the steady-state analysis of the isolated bidirectional dc-dc converter. The circuit configuration of the proposed converter is very simple. The proposed converter employs a coupled inductor with same winding turns in the primary and secondary sides. Thus, the proposed converter has higher step-up and step-down voltage gains than the conventional bidirectional DC-DC boost/buck converter. Bidirectional dc-dc converters (BDC) Have recently received a lot of attention due to the increasing need to systems with the capabilityBidirectional energy transfer betweentwo $d c$ buses. Apart from traditional application in dc motor drives, new applications of BDC include energy storage in renewable energy systems, fuel cell energy systems, hybrid electric vehicles (HEV). The bidirectional converter, has less switching losses with zero voltage switching, and has high gain buck-boost operations.. The complete PV system with a boost $d c$ to dc converter controller to regulate the $d c$ link voltage, bidirectional converter based battery charge controller, and an inverter with its associated vector mode controller is implemented in the Simulink/Simpower environment.
\end{abstract}

Index Terms: Bidirectional dc-dc converter, current-fed, solar panel.

\section{Introduction}

Bidirectional DC-DC converters are used to transfer the power between two DC sources in either direction. These converters are widely used in applications, such as hybrid electric vehicle energy systems, uninterrupted power supplies, fuel-cell hybrid power systems, PV hybrid power systems, and battery chargers. Many bidirectional DC-DC converters have been researched.Some literatures research the isolated bidirectional DCDC converters, which include the half-bridge types and full-bridge types. These converters can provide high step-up and step-down voltage gain by adjusting the turns ratio of the transformer.

The integration of photovoltaic (PV) power systems and energy storage schemes is one of the most significant issues in renewable power generation technology. The rising number of $\mathrm{PV}$ installations due to increasingly attractive economies,substantial environmental advantages and supportive energy policies require enhanced strategies for their operation in order to improve the power supply stability and reliability. Energy storage system for the PV powergenerationisaddressed in the literature. Some concentrates on the system configurations as well as control strategies whereas some others focus solely on the converter topo-logies or on the control techniques.

In the conventional PV system architecture, the PV power is transferred to the load through a unidirectional and a bidirectional converter where a considerable amount of power loss occurs in each conversion stage. Hence, the system efficiency deteriorates with the increasing number of power conversions. These disadvantages arise from the fact that bothof the converters in the conventional system process the PV array output power. In some previous applications, the battery-bank is directly connected to a dc bus without a bidirectional converter.This configuration requires more battery stacks and reduces thesystem efficiency. Also, the battery life is degraded without proper control of charging and discharging of the battery. Though series strings of storage batteries provide high voltage, a slight mismatch or temperature difference can cause charge imbalance if the series string is charged as a unit. Such high voltage batteries are expensive and produce more arcing on the switches than the low voltage batteries. Another problem with higher voltage batteries is the possibility of one cell failing. A faulty cell would produce lower voltage, however, in an extreme case,one open cell could break the current flow. A modified DC-DC boost converter is presented. The voltage gain of this converter is higher than the conventional DC-DC boost converter. Based on this converters, a bidirectional DC-DC converter is pro- posed. The proposed converter employs a coupled inductor with same winding turns in the primary and secondary sides. Comparing to the proposed converter and the conventional bidirectional boost/buck converter, the proposed converter has the following advantages: 1) higher step-up and step-down voltage gains; 2) lower average value of the switch-current under same electric specifications.

In thecustomary bidirectional converters, more switchesandtransformer-basedschemes increases production costs and reduces conversion efficiency.Moreover, the conventional PV energy storage systems use time based energy scheduling to operate the operation mode control of the battery charger based on the time 
setting. In these control methods, battery charging and discharging may be disrupted due to overcast weather. This paper addresses the above limitations of the existing works and designs a PV storage system with a wellorganized architecture having a high efficiency bidirectional converter and a novel control algorithm. The objective of this paper is to propose a control algorithm of the battery charger for photovoltaic applications, where the control strategy lies in the dc bus power and battery state of charge (SOC) estimation. An efficient bidirectional converter is included in this PV battery management system (BMS) to improve the overall efficiency.

\section{A. Power Management and Controller Implementation :}

\section{System Configuration}

The purposes of the power management and control system architecture are to satisfy the load power demand and to maintain the state of charge of the battery bank within a specified limit to prevent blackouts and to extend thebattery life. As there are two energy sources in the system, it requires managing the sources to ensure reliability, optimal operation and cost effectiveness. In this case, the PV generation profile, the residential load profile and the battery storage profile needs to be considered. Table I shows the specifications of the system. The concept of energy transfer is achieved by using a novel control algorithm incorporated with the bus power and battery SOC. A good regulation capability is achieved with the proposed control method. The control strategy used here consists of three parts. First part is the converter controller for voltage regulation, the second part is the battery charging and discharging controller using the bidirectional converter, and the third part is the inverter controller for obtaining ripple-free power.

\section{B. PV Module}

A PV module, which converts light into electricity, can be modeled as a single diode model, as shown in Fig. 3. Therelationship among different currents and and voltages of the equivalent circuit model of PV module is given by,

$$
\begin{gathered}
I_{L G}-I_{D}-\frac{V_{D}}{R_{s h}}-I_{p v}=0 \\
V_{p v}-V_{D}+I_{p v} R_{s}=0
\end{gathered}
$$

where, ILG (A) is the light generated current; ID is the diode current; VD is the diode voltage; Rsh is the shunt resistance; Rs is the series resistance; $\operatorname{Ipv}(\mathrm{A})$ and $\mathrm{Vpv}(\mathrm{V})$ are $\mathrm{PV}$ module output current and output voltage, respectively. The operating equation of the PV module can be easily

$$
I_{p v}=I_{L G}-I_{s a t}\left(e^{\frac{q}{n k T}\left(V_{p v}+I_{p v} R_{s}\right)}-1\right)-\frac{V_{p v}+I_{p v} R_{s}}{R_{s h}}(3)
$$

the PV module temperature and $\mathrm{k}$ is Boltzmann constant. The electrical output characteristics of the PV module are shown in Fig. 4. This figure is exposed to a specified amount of irradiance $(1000 \mathrm{Wm}-2)$ at a constant ambient temperature $(250 \mathrm{C})$. The PV panel is operated usually at or near maximum power point (MPP) for optimum performance of the system. A Simulink model of the PV module, the used as the PV source. This model takes solar irradiance and PV module current as input and gives PV module voltage and power as the output. Different parameters of the circuit, such as short circuit current, open circuit voltage, current and voltage at MPP can also be set in the model.

\section{DC/DC Converter Control}

The dc link collects the energy generated by the PV source and delivers it to the load and, if necessary, to the battery banks. A classical boost converter is used as the dc-dc conversion interface. The utility ac voltage is usually $230 \mathrm{~V}$ and thus requires a dc voltage of about $380 \mathrm{~V}$ at the output of the dc-dc converter. Since the voltage of PV module is usually below this level, the system raises the voltage level using the boost converter. The hysteresis current control (HCC) methodthe used as the converter controller to stabilize the voltage level of the dc bus. This method operates at a variable frequency. The hysteretic controller provides the gating signal for switch on-off as necessary to maintain a waveform within a given limit.

\section{Dual Active Bridge, DAB:}

As shows in fig a common IBDC topology whichis sometimes called dual active (full) bridge (DAB). In this configuration, full-bridge voltage-fed converters are used at both sides of the isolation transformer and the control is performed based on soft-switched phase-shift strategy. In its basic form, the diagonal switching pairs in each converter are turned on simultaneously with 50\% duty cycle (ignoring the small dead time) and with 180 degrees phase shift between two legs to provide a nearly square wave ac voltage across 
transformer terminals. The phase shift between two ac voltages, denoted by $\mathrm{f}$, is an important parameter which determines the direction and amount of power transfer between dc buses. Byadjusting this phase shift, a fixed frequency operation with full control over the powertransfer is possible.

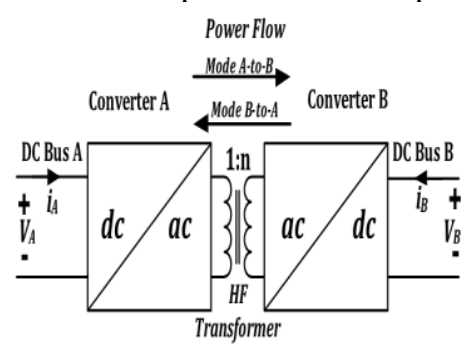

Fig.1. Basic structure of an IBDC

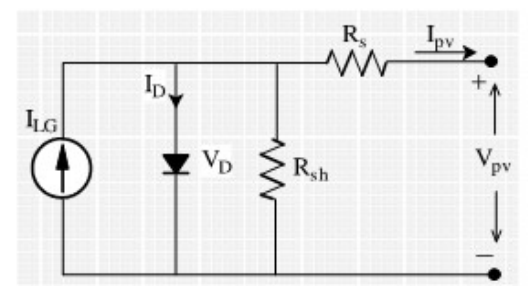

Figure 2.Equivalent circuit of PV module.

\section{E. Bidirectional Converter Control}

The efficiency, reliability and dynamic performance of the system relies on the operation of the bidirectional converter under different modes of operation, so that individual parts of the system can operate properly. A buck-boost type high performance bidirectional converter, is used to charge and discharge the battery. This bidirectional converter is having the following properties which enhance its performance,

- power flow with large voltage diversity

- high step-up and step-down ratio

- soft switching and zero voltage switching

- reduced switching losses due to fewer switches

- less conduction losses

The voltage gain of the bidirectional converter in the buckstate can be expressed as, $G_{V 1}=\frac{V_{L}}{V_{H}}=\frac{d_{3}\left(1-d_{3}\right)}{N\left(1-d_{3}\right)+1}$

and the voltage gain of the bidirectional converter in theboost state can be represented as,

$$
G_{V 2}=\frac{V_{H}}{V_{L}}=\frac{2+N}{1-d_{1}}
$$

where, $\mathrm{VL}$ and $\mathrm{VH}$ are the battery terminal voltage and dc link voltage respectively. $\mathrm{d} 3$ and $\mathrm{d} 1$ are the duty cycle of switch S3 and S1 respectively. N is the turn ratios of the coupled inductor LP and LS, as shown The proposed battery charger algorithm uses the data obtained from the dc bus power and thebattery state of charge. De- pending on the system operatingconditions, theoperation mode controller generates the mode selection control signal. To balance the power flow in the system and to achieve the power conditioning compatibility, this controller operates readily. The battery SOC would be adjusted to match the power demand of the load. For this reason, the inner power loop goes with outer battery SOC to adjust the charging algorithm.

If the battery SOC is below $90 \%$ and the dc link has sufficient power from the PV module to charge the battery, then the bidirectional converter acts as a buck converter and charges the battery. On the other hand, if the battery SOC is above $40 \%$ and the load needs support from the battery, then the bidirectional converter acts as a boost converter and delivers power from the battery to the load. Whenever the battery is overcharged or has no sufficient charge to deliver, then it automatically goes to the halt mode. Control of the 


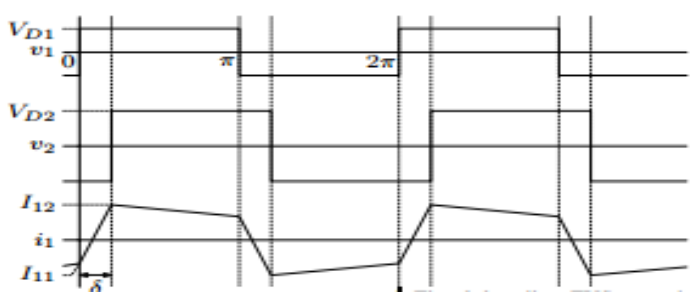

Fig. 4. Simplified theoretical waveforms used to analyze the power losseswhen VD1< VD2

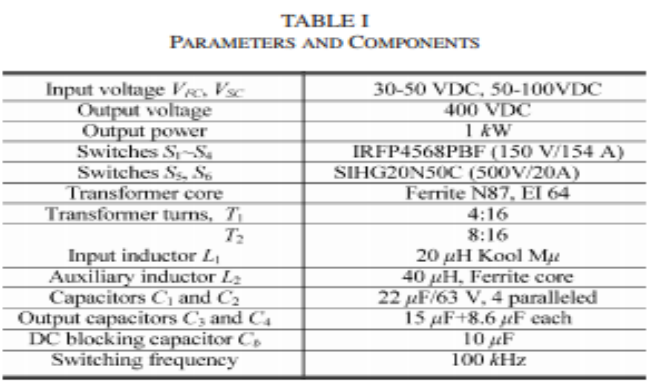

bidirectional converter is the key factor of the power management. To manage the energy exchanges between the dc link, the PV module and the storage device, three operating modes are employed which are charging,discharging and half mode.

\section{Quasi-Optimal Design Method}

To increase the conversion efficiency, generally based on theprecise mathematic model of the power loss of each componentand the converter switching times, the phase-shift angle, andthe duty cycle can be calculated to control the converter andmake the total power losses minimal. But this method hastwo critical limitations in practice: 1) performance will sufferwhen the loss models employed in the circuit and the switchingtimes are not available or not precise; and 2) the controller withthe needed phase-shift angle and duty cycle depending on thevariable input voltage and output power is complex to design.

Hence, a quasi-optimal design is proposed here which includestwo design criteria.

1) Minimize the RMS value of iL2 by the phase-shift andduty-cycle control to reduce the conduction losses.

2) Keep the ZVS operation for HV-side switches to reducethe switching losses. The RMS current flowing through the secondary inductor iscalculated, as shown, at the bottom of this page. The secondary-side RMS current is plotted in

Fig. 9(a) according to phase-shift angles and duty cycles under the condition where the output power is $1 \mathrm{~kW}$; the outputvoltage is $400 \mathrm{~V}$; the interface inductance is $40 \mu \mathrm{H}$, and theswitching frequency is $100 \mathrm{kHz}$. When the input voltage or theduty cycle varies, the phase-shift angle may be recalculated by(1) to get the required output power or dc-bus voltage. It can beseen that based on the input voltage and the phase-shift anglefrom (1), adjusting the duty cycle value can reduce the current RMS value effectively. Furthermore, using duty-cycle controlcan extend the soft-switching range for the HV-side switches,S5 and S6, as shown
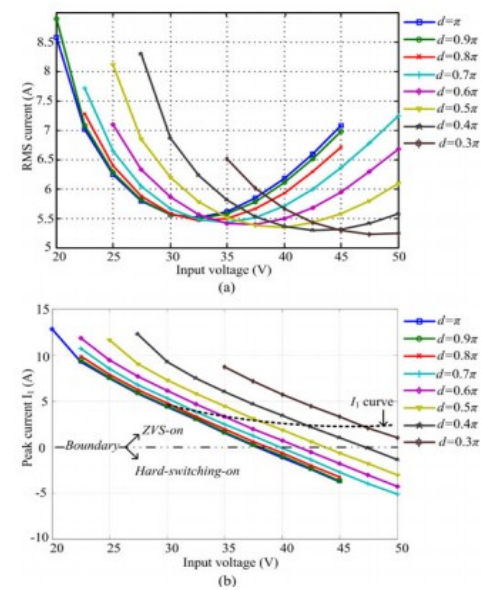

Fig.5 Typical current values with phase shift plus duty-cycle control under the boost mode: (a) secondary current RMS values, and (b) peak current values $i_{L 2}$ at time $t_{2}$. 


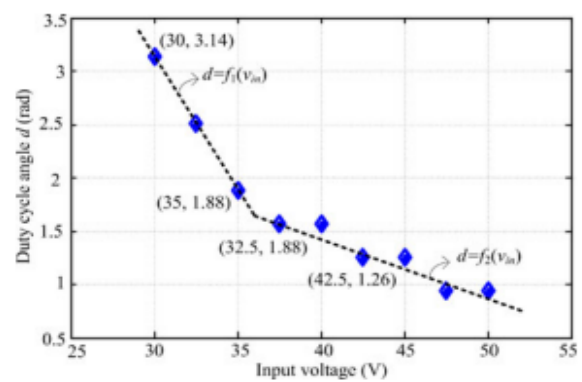

Fig.6 Relationship between the duty cycle and variable input voltage

The I1 curve (dashed line) is the approximate track which is followed by current Il and there is a margin between the I 1 curve and boundary curve, which is related to the energy stored in the L2 for achieving completely resonance during the dead time of switch commutation.From Fig.4,an approximate relationship between input voltage and duty cycle can be derived as illustrated.

The analysis conducted here revealed that there is a valuedoptimal that can minimize the ac RMS current and extend theZVS range to achievequasi-optimaloperation.Hence, variable $\delta$ is used to control the required power transferred by the converterand variabledischosen to increase the efficiency. The algorithmto decide $\delta$ and $\mathrm{d}$ is implemented by the following steps.

1) Find the value doptimal that minimizes RMS current byequating the first derivative of (13) to zero with respect tod for the input voltage VFC or VSC, the output voltage Voand the required output power Po.

2) Determine $\delta$, using (1). If $\delta<0$ or cannot find real root,set $\delta=0$, and recalculate $\mathrm{d}$ by (4).

3) Test the value of I. If I1 $<0$, reduce $d$ and then go backto step 2 to recalculate $\delta$.

4) Using calculated $\delta$ and d, generate the driving signals forthe power switches.

In this paper, according to the variable input voltage andthe required output power, the quasi-optimal designed $\delta$ and dcan be calculated offline. During the hardware test, the onlinelook-up table is used in the digital signal processor to controlthe converter effectively

\section{Simulation results:}

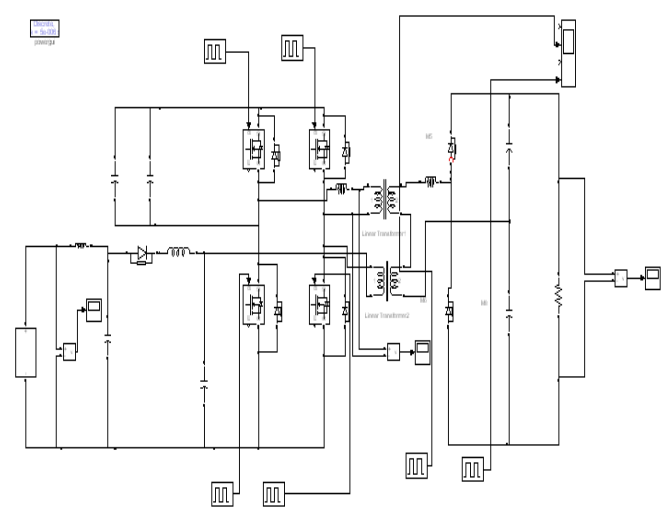

(a)

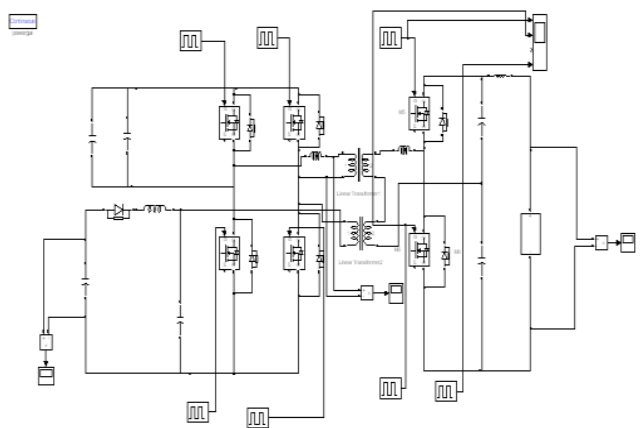

(b)

Fig.7 Bidirectional DC-DC converter simulation circuit (a) forward mode and (b) reverse mode.

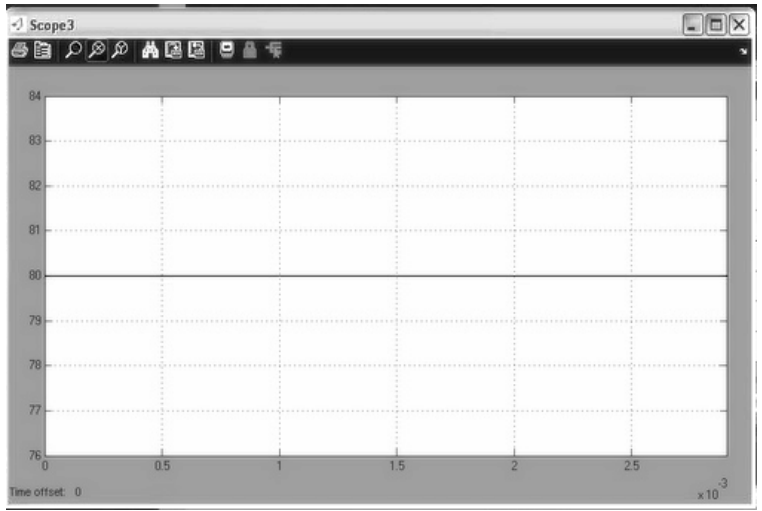

Fig.8 input voltage of solar panel in forward mode 


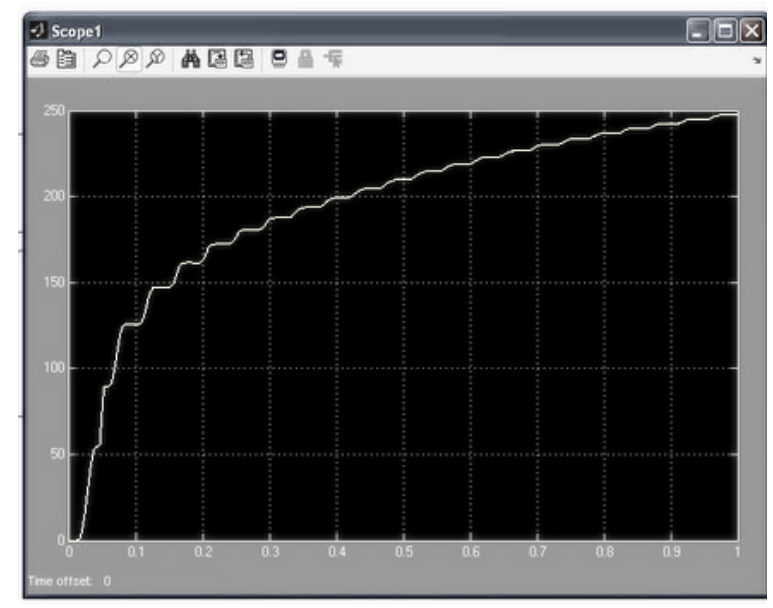

Fig.9 output voltage in forward mode

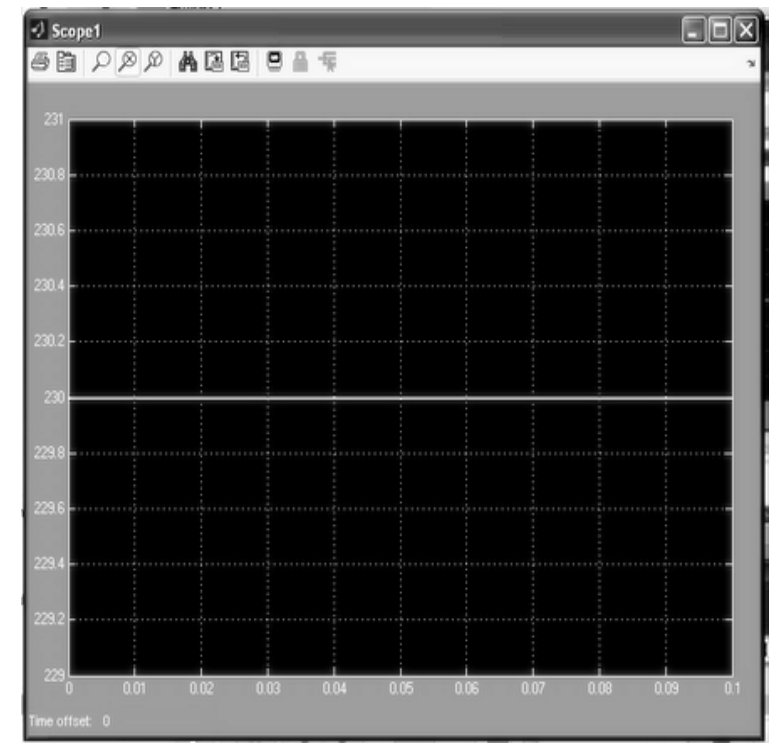

Fig.10 Input voltage of solar panel in reverse mode

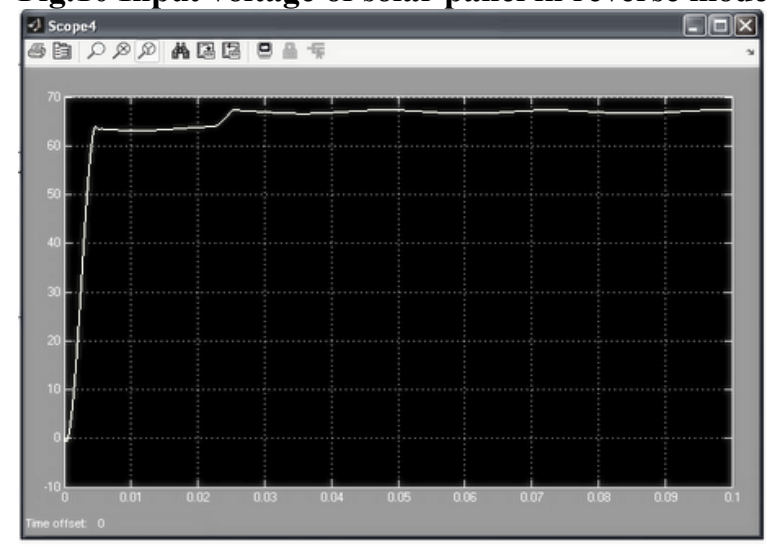

Fig.11 output voltage in reverse mode

\section{Conclusion:}

A novel hybrid bidirectional dc-dc converter consisting of acurrent-fed input port and a voltage-fed input port was proposedand studied. Using the steady-state analysis, the relationship between the voltage gains of the proposed converter giving input from PV panel was presentedto analyze the power flows. The simple quasi-optimal design method was investigated to reduce the current ac RMS currentand extend the ZVS range. Experiments showed good agreement with the theoretical analysis and calculation. Additionally,the experimental results reveal that the duty-cycle control caneffectively eliminate the reactive power and increase 
the efficiency when input voltage is varied over a wide range. improve the overall efficiency of the proposed system.

\section{References:}

[1] Bai H. \&Mi, C. (2008). Eliminate Reactive Power and Increase System Efficiency of Isolated Bidirectional Dual-Active-Bridge DCDC Converters Using Novel Dual-Phase-Shift Control. IEEE Transactions on Power Electronics, Vol. 23, No. 6, (Nov. 2008), pp. 2905-2914, ISSN 0885-8993

[2] De Doncker, R.W.A.A., Divan, D. M. \&Kheraluwala, M. H. (1991).A three-phase softswitched high-power-density DC/DC converter for high-power applications. IEEE Transactions on Industry Applications, Vol. 27, No. 1, (Jan./Feb. 1991), pp. 63-73, ISSN 0093-9994

[3] Inoue, S. \&Akagi, H. (2007). A Bidirectional DC-DC converter for an Energy storage system With Galvanic Isolation. IEEE Transactions on Power Electronics, Vol. 22, No. 6, (2007), pp. 2299-2306, ISSN 0885-8993

[4] Jain, A. K. \&Ayyanar, R. (2010). PWM Control of Dual Active Bridge: Comprehensive Analysis and Experimental Verification. IEEE Transactions on Power Electronics, Vol. PP, No. 99, (2008), pp. 1, ISSN 0885-8993

[5] Kheraluwala, M. N., Gascoigne, R. W., Divan, D. M. \& Baumann E..D.(1992). Performance characterization of a high-power dual active bridge DC-to-DC converter," IEEE Transactions on Industry Applications, Vol. 28, No. 6, (Nov./Dec. 1992), pp. 1294-1301, ISSN 0093-9994

[6] T.Funaki“"Evaluating energy storage efficiency by modeling the voltageand temperature dependency in EDLC Electrical Characteristics," IEEETrans. Power Electron., vol. 25, no. 5, pp. 1231-1239, May 2010.

[7] H. Matsumoto, "Charge characteristics by exciting-axis voltage vibrationmethod in boost driver with EDLCs," IEEE Trans. Power Electron.,vol. 25, no. 8, pp. 1998-2009, Aug. 2010.

[8] D.D.-C. Lu and . G. Agelidis, "Photovoltaic-battery-powered DC bussystem for common portable electronic devices," IEEE Trans. PowerElectron., vol. 24, no. 3, pp. 849-855, Mar. 2009.

[9] J. Shen, K. Rigbers, and R. W. De Doncker, "A novel phase-interleaving algorithm for multiterminal systems," IEEE Trans. Power Electron., vol. 25,no. 3, pp. 741-750, Mar. 2010.

[10] Z. Zhang, O. C. Thomsen, and M. A. E. Andersen, "A two-stage dc-dcconverter for the fuel cell-supercapacitor hybrid system," in Proc. IEEEEnergy Convers. Congr.Expo., Sep. 2009, pp. 1425-1431. 